\title{
Open Data: A Paradigm Shift in the Heart of Government
}

\author{
Ali M. Al-Khouri \\ Director General, Emirates Identity Authority, UAE \\ Professor of Identity and Security, British Institute of Technology and E-commerce, UK \\ E-mail: ali.alkhouri@emiratesid.ae
}

Accepted: August 04, 2014

Doi:10.5296/ jpag.v4i3.6407 URL: http://dx.doi.org/10.5296/ jpag.v4i3.6407

\begin{abstract}
In today's global economy, governments are coming to comprehend new realities and adopt new approaches to cope with the paradigm shift in citizens' relations. Among the different trends in recent years is the concept of open data where it requires governments placing more data for public consumption. The use and reuse of open data is argued to contribute to enormous potential for economies and citizens welfare. This article attempts to explore and provide a short overview of the concept of open data and its current applications. The primary contribution of the article is the presentation of a case study of how the United Arab Emirates (UAE) government envisages using open data to develop decision support models to improve public service delivery and primarily citizens' quality of life. The presented approach aims to promote discussion among policy and decision-makers and fuel debate and knowledge development in this critical and evolving field of practice.
\end{abstract}

Keywords: Open government, open data, e-government, participation, transparency 


\section{Mll Macrothink}

\section{Introduction}

Governments the world over are in the throes of citizen centric transformation. In the quest for better service delivery mechanisms, governments are moving away from conventional governance systems into adopting more dynamic citizen centric business models and practices. Indeed, governments have achieved worthy progress in fields of public service delivery through various e-government initiatives, specifically in the past two decades with gigantic investments in information and communication technologies (ICT).

As per a recent UNDP report, 217 e-government projects are reported active across 89 countries globally that worth 211 million USD in 2012 (UNDP, 2013). According to Gartner, worldwide IT spending by government organizations was projected to total $\$ 449.5$ billion $^{1}$ in 2013 (Gartner, 2013a).

Such investments are linked to the rapidly evolving technological developments that have heightened citizens' expectation bars to new levels, pressuring government to radically revolutionize how they communicate, inform, interact and transact with their citizens. The same developments are redefining the parameters for government transformation with emphasis on becoming more open than ever before.

Opening up government data to free public access is a global trend though. It focuses on generating value through re-use of specific types of data - public sector information, sometimes also referred to as government data. Proponents of such concepts argue that increased data transparency provide the basis for public participation and collaboration in the creation of innovative, value-added services, and improve the decision making capabilities of both governments and individuals (Ubaldi, 2013; see also: Manyika, 2013). See also Figure 1 .

\footnotetext{
${ }^{1}$ From our practical experience in the field, we believe such reports only provide conservative numbers, where in reality, governments annual expenditure in technology infrastructure on a global scale may well exceed trillions of dollars. Governments themselves face difficulty to accurately calculate both direct and in-direct costs. Several reasons may be cited, but the primary reason being in the nature of this divergent octopus-like multi related branched field of practice.
} 


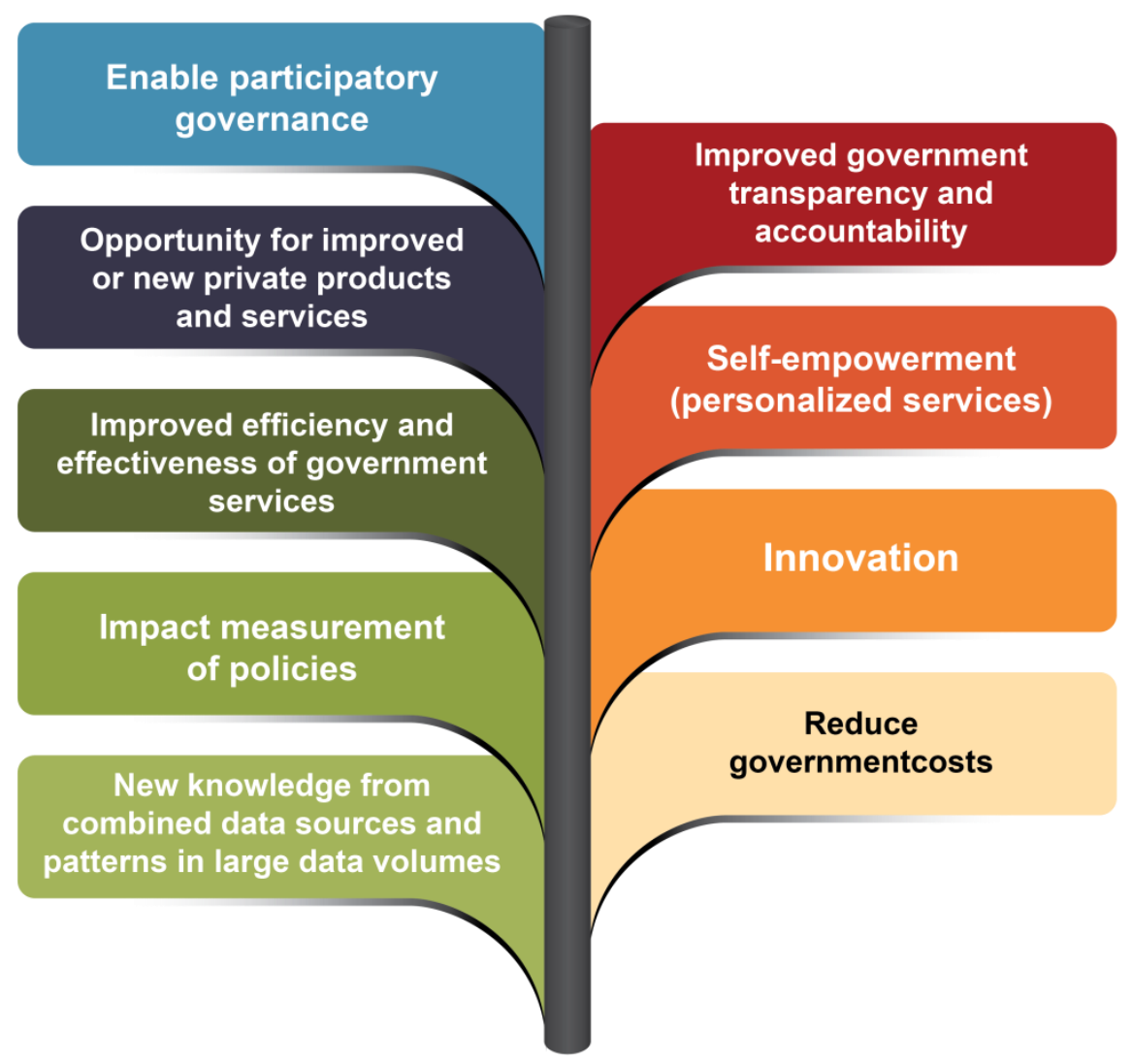

Figure 1: Open Data Opportunities in Government Context

The purpose of this article is to explore the field of open data in government context. The primary objective of the article is to illustrate how the UAE government envisages using open data to develop decision support models to improve public service delivery and citizens' quality of life. This is aimed to trigger debate and discussion among planners, policy and decision-makers and support knowledge development and enhancement of this critical and evolving field of practice.

The article is structured as follows. In section 2, an introduction is provided on the concept of open data and what it means. In section 3, the use and application of open data in government domain is explained, as well as the perception surrounding it, both from threat and opportunity perspectives. In section 4 , we shed light on possible collaboration scenarios between public and private sectors, as the latter sector is seen as the one driving the game. In section 5, we talk about open data in UAE government and how it envisages its evolution phases in the coming few years. The article is then concluded in section 6 with reflections and possible areas of further research. 


\section{Open Data: What does it Really Mean and what are its Promises?}

"A piece of data or content is open if anyone is free to use, reuse, and redistribute it subject only, at most, to the requirement to attribute and/or share-alike."

- opendefinition.org

Open data means that certain data should be freely available to everyone to use and republish as they wish, without restrictions from copyright, patents or other mechanisms of control (see also: Open Data Handbook, 2012). The goals of the open data movement are similar to those of other 'open' movements such as open source ${ }^{2}$, open hardware ${ }^{3}$, open content ${ }^{4}$, and open access 5 .

In principle, open data is all about data dissemination and information reconstruction. One may also wonder why does open data become important in government. Why does data dissemination then become so important? The answer lies in the concept of government transformation itself. For governments to evolve and transform into citizen centric operational models; data needs to be shared and shared proactively.

Unfoundedly, governments by design collect and generate huge amounts of data. The extraordinary quantity and centrality of data collected by governments make these data particularly significant as a resource for increased public transparency and public awareness and to generate insights into how to improve government performance (Ubaldi, 2013).

As depicted in Figure 2, open data can be visualized with the three dimensions of (1) availability and accessibility, (2) reusability and redistribution and (3) universal participation. To operate effectively, the interoperability between the three dimensions is considered key to create value.

\footnotetext{
${ }^{2}$ In production and development, open source as a development model promotes a universal access via free license to a product's design or blueprint, and also a universal redistribution of that design or blueprint, including subsequent improvements to it by anyone (Gerber et al., 2010; Lakhani and von Hippel, 2003). Researchers view open source as a specific case of the greater pattern of Open Collaboration, any system of innovation or production that relies on goal-oriented yet loosely coordinated participants, who interact to create a product (or service) of economic value, which they make available to contributors and non-contributors alike (Levine and Prietula, 2013).

${ }^{3}$ Open source hardware means that information about the hardware is made publicly available so that anyone can study, modify, distribute, make, and sell the design or hardware based on that design.

${ }^{4}$ Open content or OpenContent is a neologism coined by David Wiley in 1998 which describes a creative work that others can copy or modify (Grossman, 1998; Wiley, 1998).

${ }^{5}$ Open access means unrestricted online access to peer-reviewed scholarly research. Open access is primarily intended for scholarly journal articles, but is also provided for a growing number of theses, book chapters, and scholarly monographs (Schöpfel and Prost, 2013; Schwartz, 2012; Suber, 2011).
} 


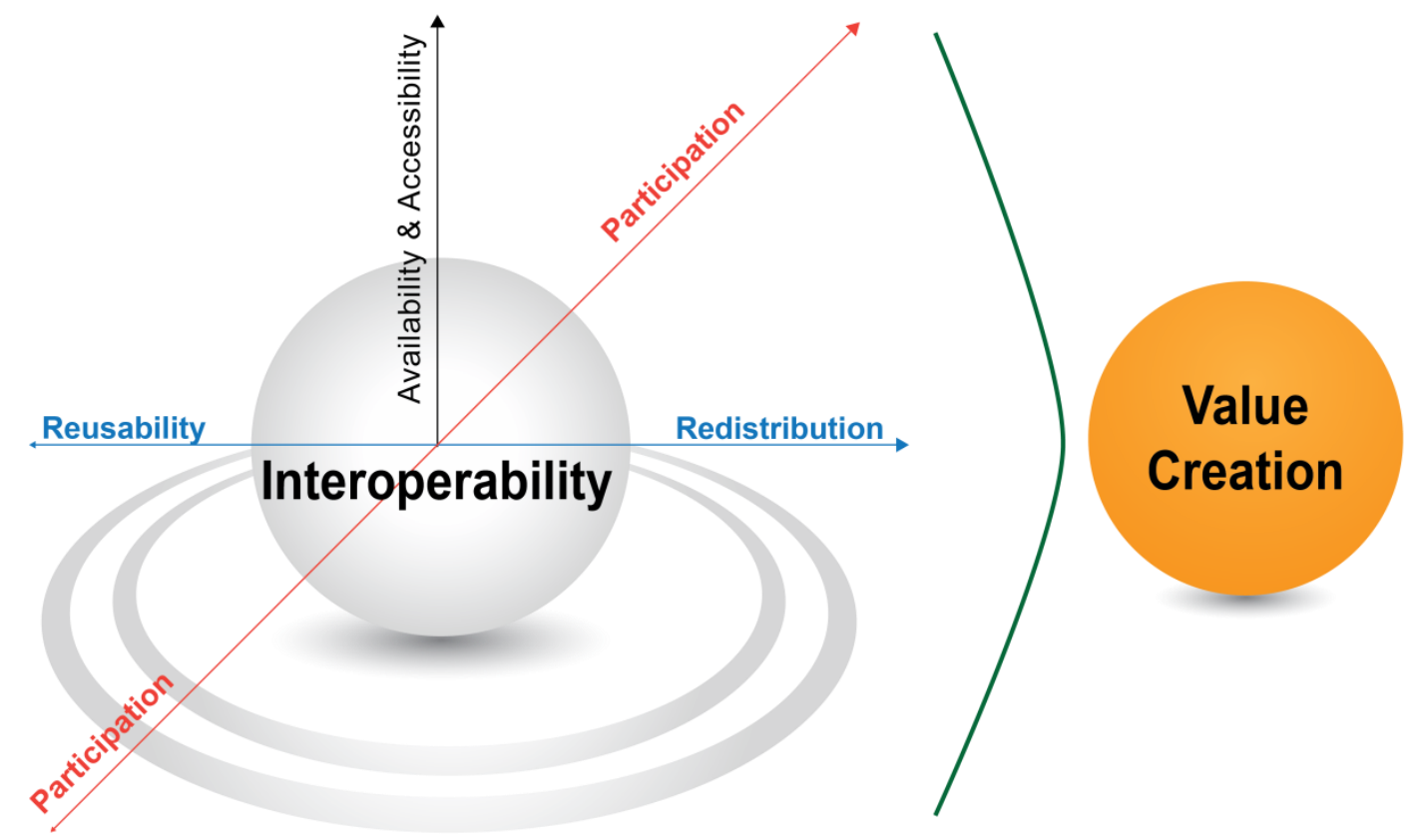

Figure 2: Open Data Dimensions

- Availability and Accessibility: The data must be easily available (preferably as a download on the internet) and free to access without any restrictions or access control.

- Reuse and Redistribution: Being free in nature, the data should be free to be redistributed and reused as deemed fit by the user.

- Universal Participation: everyone must be able to use, reuse and redistribute - there should be no discrimination against fields of endeavor or against persons or groups, e.g., commercial use, non-commercial use, research use, educational purpose etc. should not be limiters.

Open data is seen to correlate with concepts like big data; a term referred to data sets that are voluminous, diverse, and timely (McKinsey, 2013). The degree to which big data is 'liquid' indicates whether or not the data sets are open. Open data is also seen to be associated with concepts like "MyData," which involves sharing information collected about an individual (or organization) with that individual. See also Figure 3. 


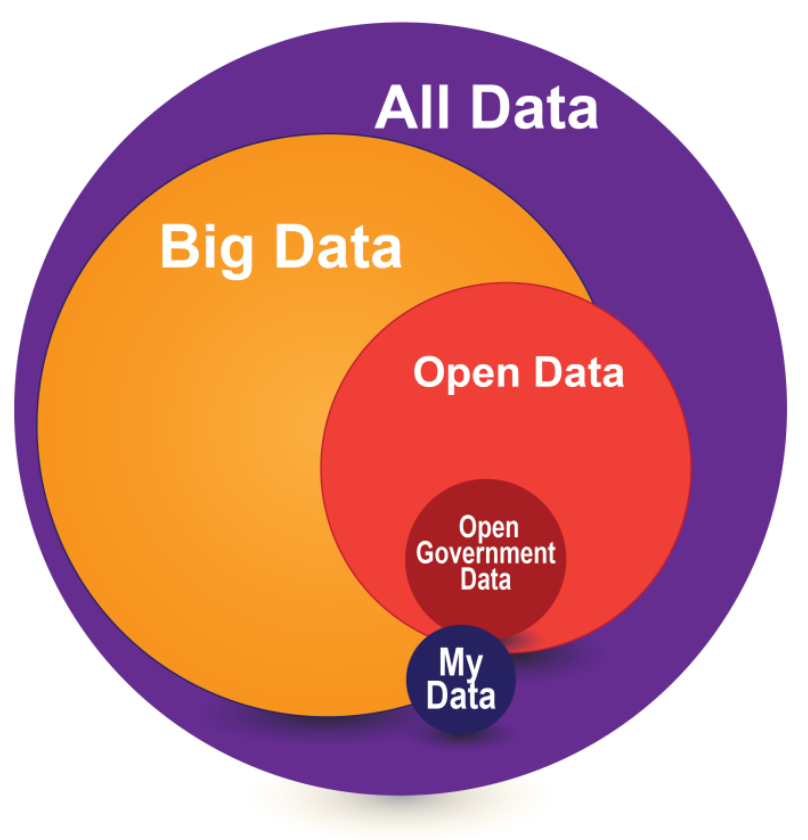

Figure 3: Open Data Relations to other Data Concepts

Source: Manyika, 2013

Making data more 'liquid' (i.e., open, widely available, and in shareable formats) is largely argued to have the potential to unlock large amounts of economic value (Manyika, et al., 2013). A study published by McKinsey Global Institute in October 2013 reported that open data has the potential to unlock between $\$ 3.2$ trillion and $\$ 5.4$ trillion in additional economic value annually across a variety of industries in US alone (McKinsey, 2013). According to European Commission (2011) overall economic gains from opening up this resource could amount to $€ 40$ billion a year in the European Union (EU). The commission also stated the following four primary reasons for supporting open data initiatives in EU governments, which are very much similar to other advocators:

- Public data has significant potential for re-use in new products and services;

- Addressing societal challenges - having more data openly available will help us discover new and innovative solutions;

- Achieving efficiency gains through sharing data inside and between public administrations;

- Fostering participation of citizens in political and social life and increasing transparency of government.

See also Figure 4. 


\section{Macrothink}

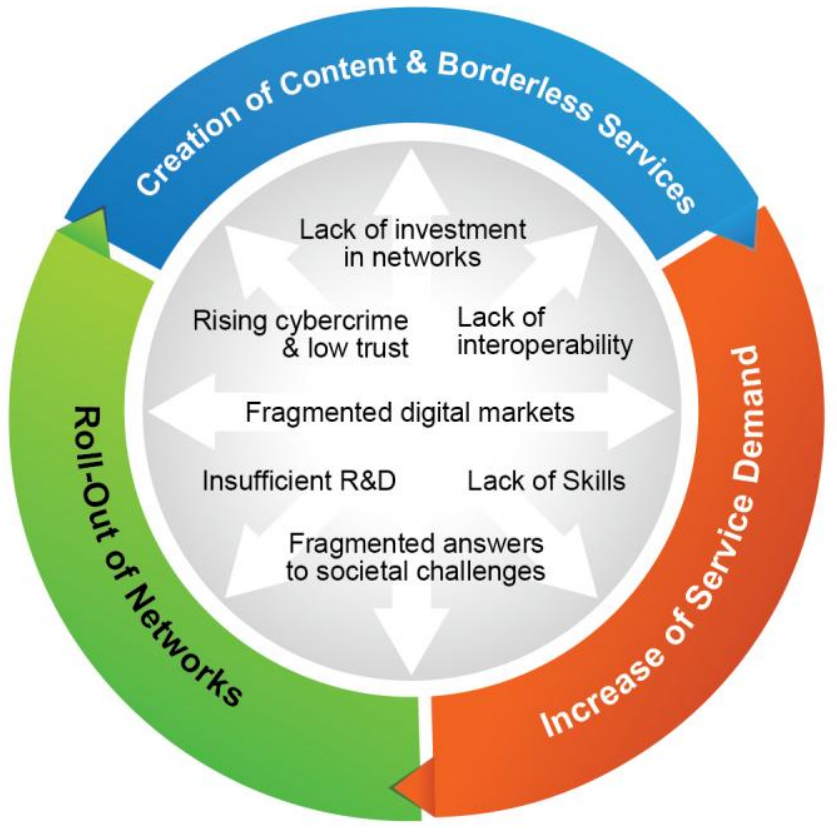

Figure 4: EU Open Data Drivers

Source: European Commission (2011)

The drive towards open data is further driven by the internet access, connectivity, lack of full interoperability, issues of cyber security and other such factors as defined in the Digital Agenda of Europe (European Commission, 2011). A common assumption when opening government data is that simply supplying more data freely and in more formats will lead to more use (Helbig et al., 2012). In general, government data that provides value to citizens is characterized by five dimensions: timeliness, relevance, meaningfulness, usability, visualization. See also Figure 5. It is in this context that we examine the characteristics of government open data. Government data gets characterized by five dimensions as depicted in Figure 5.

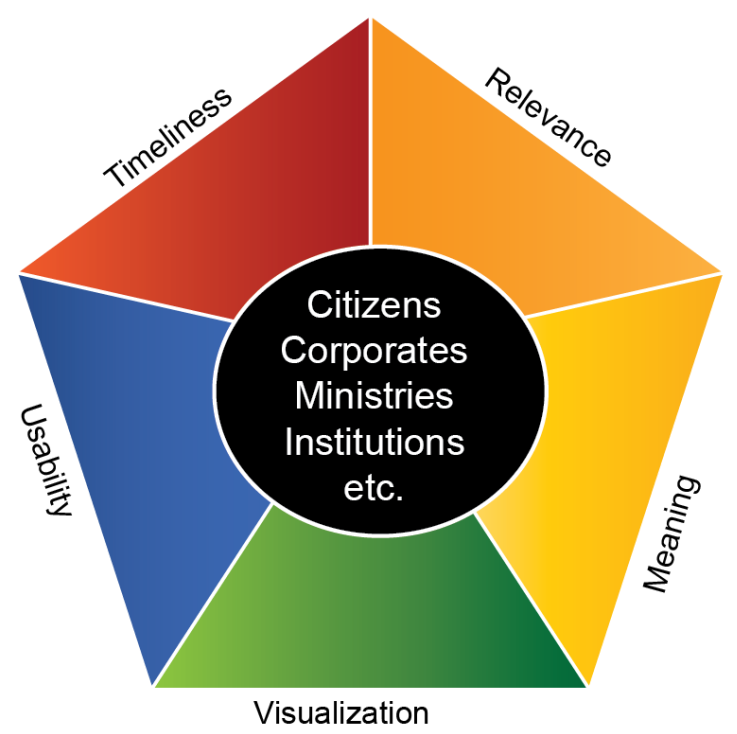




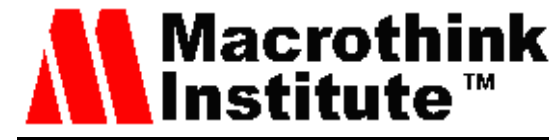

Figure 5: Five Dimensions of Government Data Characteristics

These dimensions characterize the value of the open data. "Timely" publication of data in the public domain, publication of "relevant" data for public consumption, "meaningful" data publication, and providing the ability to "visualize" data for semantic consumption ultimately defines the "usability" of data by different interest groups and determines the value of the data.

What is the use of data if it is not relevant? What is the use of data if it is meaningless? What purpose does it serve if the data is outdated or unusable? Key to the sets of open data then is the Visualization. Data needs to be visualized to so that information can be construed.

All in all, a holistic approach is indeed needed to enhance planners and decision makers understanding of how open data initiatives can play out in and affect rapidly changing contexts of government transformation (Helbig et al., 2012). Let us elaborate further on the interconnections between government transformation and open data in the following section.

\section{Government Transformation and Open Data}

"Open data is about taking government records, public records, and putting them in the public domain where they are made freely available on a regular/timely basis to private citizens, civil society, and institutions, so that they can be reused to provide better services and to create jobs." (Rohlin, 2014)

Since the invention of the Internet, governments have been striving to achieve various transformation initiatives through e-government programs. Government transformation has been of course facilitated and accelerated by the growth in technologies. In fact, e-government transformation is seen to be the product of the evolution of the information and communication technologies. See also Figure 6.

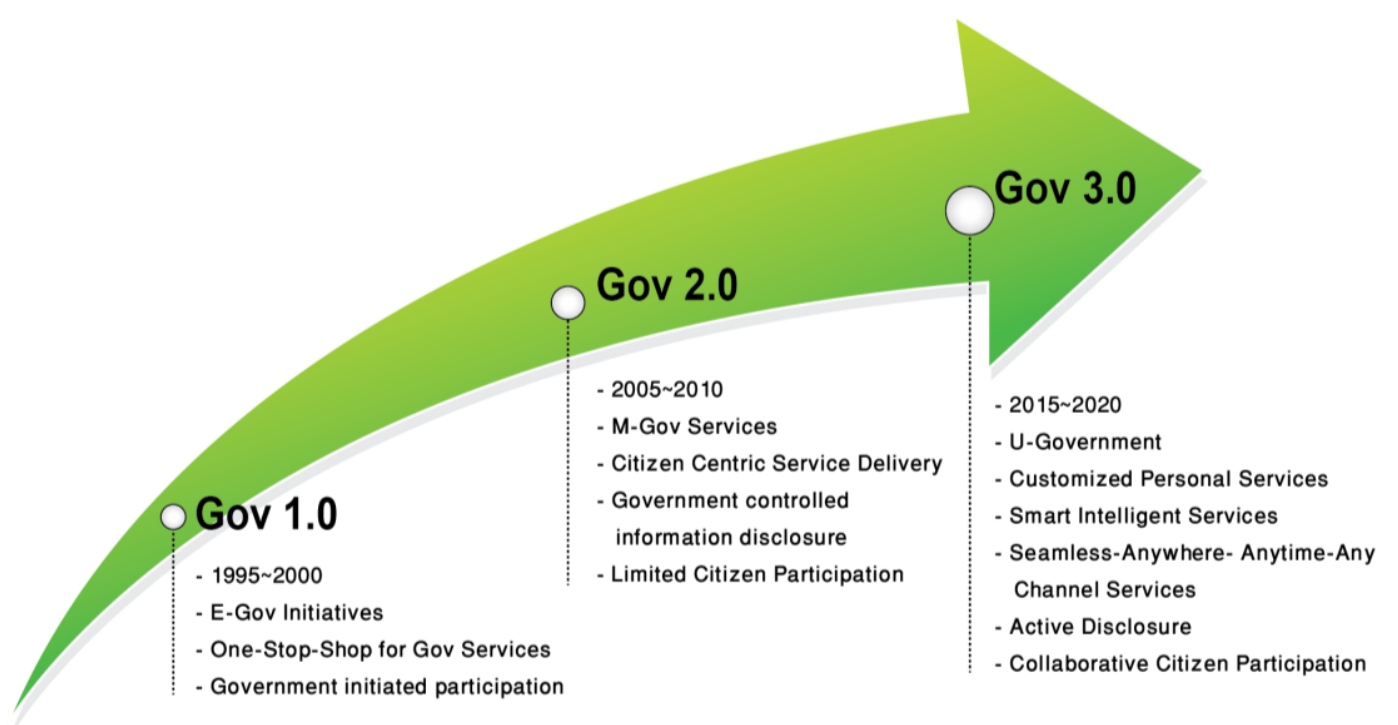

Figure 6: Government Evolution 


\section{Macrothink}

As compared to the early days of e-government, spanning the years of 1995-2000 where governments started to have their presence on the web with uni-directional information, they are today at the point where several services are delivered on the web. Governments nowadays rely heavily on web channels to facilitate services through online transactions and payments.

At present, e-government is facing the next wave of transformation; construed as Gov 3.0 as depicted in the above diagram where smart and intelligent services are sought to be delivered on demand ubiquitously across any channel of communication and irrespective of the form factor e.g., through PCs, smart phone, mobile tablets, etc. This is pushing governments to be available and accessible on a $24 \mathrm{hr}$ basis; from anywhere and in any form. Thus, more ubiquitous presence of governments is necessitated in today's digitally evolving world. This is envisaged to naturally lead to more personalized service as an 'on demand' service for every individual.

Another fundamental aspect in Gov 3.0, is related to the 'e-government' notion which is transforming into 'my-gov' notion. In such scenarios, government departments need not just be connected with citizens, but to be interconnected as well, share information in real time and disseminate information to every stakeholder.

Social media has opened up unprecedented new possibilities of disseminating information and connecting citizens with governments (Lee and Kwak, 2012). The growing numbers of users on social media platforms represent substantial opportunities for governments. Figure 7 depicts an example of a few of them. These are massive user numbers. Numbers that cannot be ignored. Governments are coming to realize the need to morph their online presence to social media interactions.
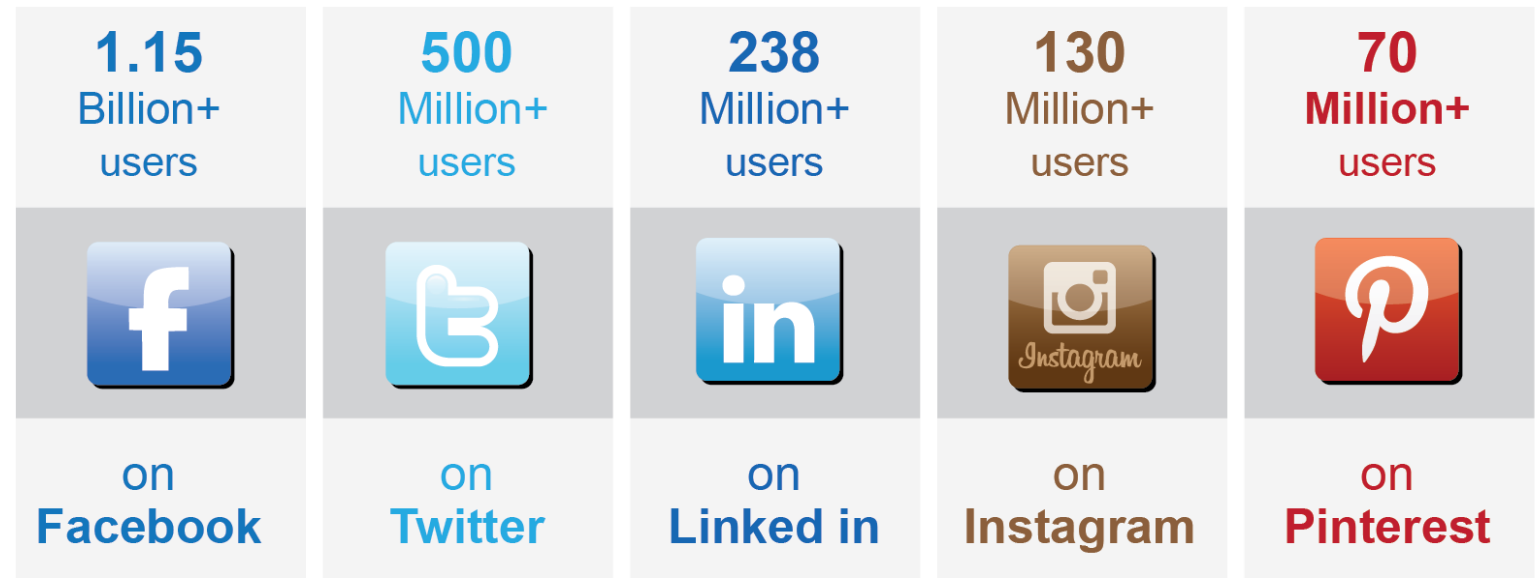

Figure 7: Social media users

Indeed, the transformative capabilities that social media technologies can bring to governance and government are substantial (Bertot et al., 2010). The interactive and instant capabilities and the increasingly pervasive nature of social media technologies can create new ways of 
democratic participation, pressures for new institutional structures, and processes and frameworks for open and transparent government on an unprecedented scale (Bertot et al., 2010).

Apparently, advanced uses of social media should fulfill commitments to open government and reflect 'joined-up government' efforts envisioned by national development strategies (Schwalje, W. and Aradi, 2013). However, unlike corporates and enterprises where single data repositories can be designed and implemented, governments typically operate out of several data silos. The fact that this data exists in individual isolated silos makes the data dissemination in public domain complex.

Each data silo needs to be interconnected. All information barriers are to be removed enabling smooth transactions. This could be achieved by having a centralized data repository (which is rather impractical) or decentalise it by allowing each department's to publish its data in the public domain. This is the basis of open government and government data. The next section expands on the different views surrounding government data and associated challenges.

\section{Government Data: Global Trends}

In general, there are so many questions that surround open data in governments today. Often data dissemination is frowned upon by government departments citing issues of security and a widespread fear of losing control. Some argue that such perceptions are due to lack of awareness among public organizations of the potential of open data (European Commission, 2011).

Many counties have passed legal strictures guaranteeing access to information. As can be seen in Figure 8, most of the world has some regulation or a formal law in place for providing freedom and right to information ${ }^{6}$.

\footnotetext{
6 The United Nations defines Freedom of Information (FOI) as the right to access information held by public bodies. It is an integral part of the fundamental right of freedom of expression, as recognized by Resolution 59 of the UN General Assembly adopted in 1946, as well as by Article 19 of the Universal Declaration of Human Rights (1948), which states that the fundamental right of freedom of expression encompasses the freedom to "to seek, receive and impart information and ideas through any media and regardless of frontiers".
} 


\section{Macrothink}

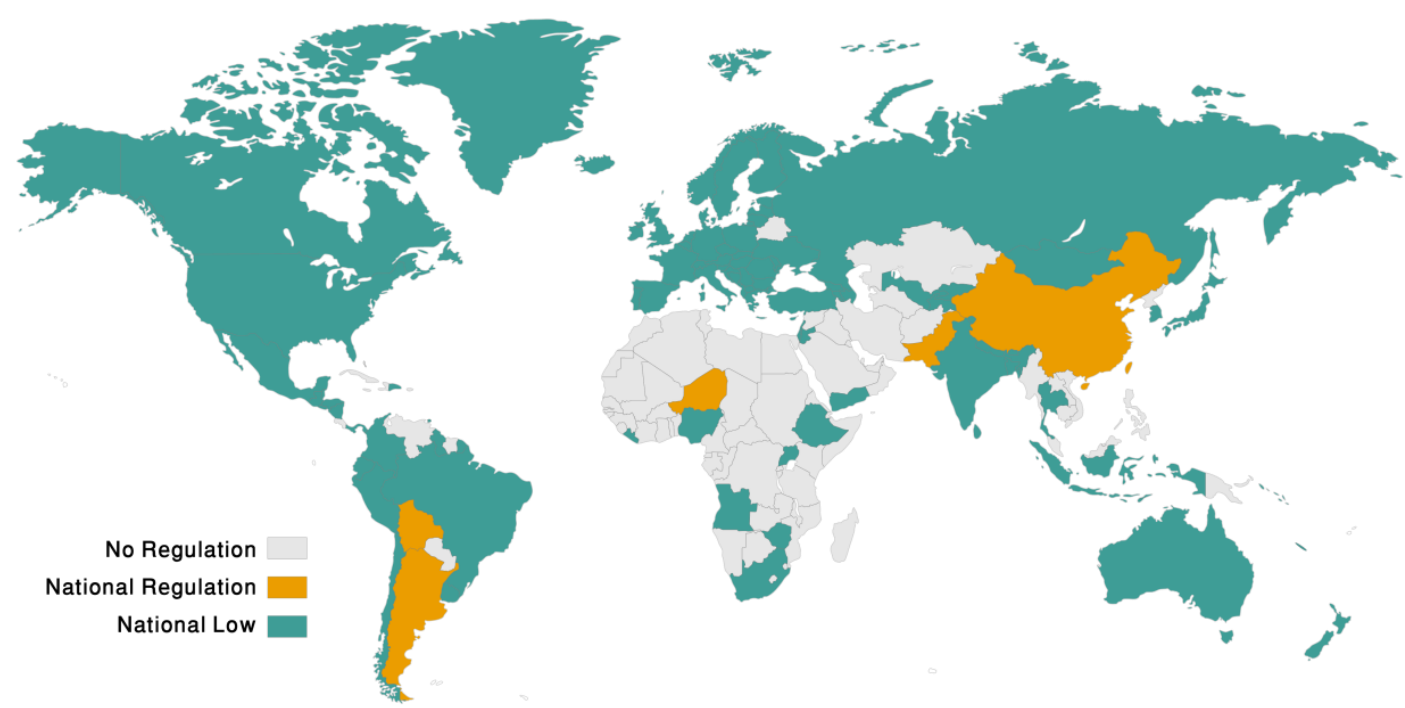

Figure 8: Government Data- Freedom on Information

Source: Article 19 http://www.article19.org

In countries where no regulation exists, reasons are attributed to the political system, but are largely related to security perceptions. To an extent, border security and associated instability are contributing to governments withholding data. This is leading to misplaced policies of restrictions and controls on access to otherwise public data. The citizen centricity is starkly missing here and there is no transformation in the services or service delivery.

Although some of the concerns are legitimate, such as privacy protection, national security and the need to protect the intellectual property rights of third parties, other arguments seem to be rather excuses for inaction (European Union, 2011). However, there seems to be an international consensus and stronger views believing that data dissemination would lead to national knowledge and ultimately better serving citizens. In fact, there are several initiatives in this direction and measurements being monitored by organizations like the United Nations, World Economic Forum, OECD, and many others.

The Open Knowledge Foundation provides measurements comparing different governments on their openness of their data (Open Data Index, 2014). See also Figure 9. Based on 11 different assessment criteria ranging from availability of data, accessibility to data, digital format availability, timeliness and frequency of updates 77 countries around the world have been ranked for their data openness for the preparation of a unique open data index. Currently this serves as a measure for open government data. 


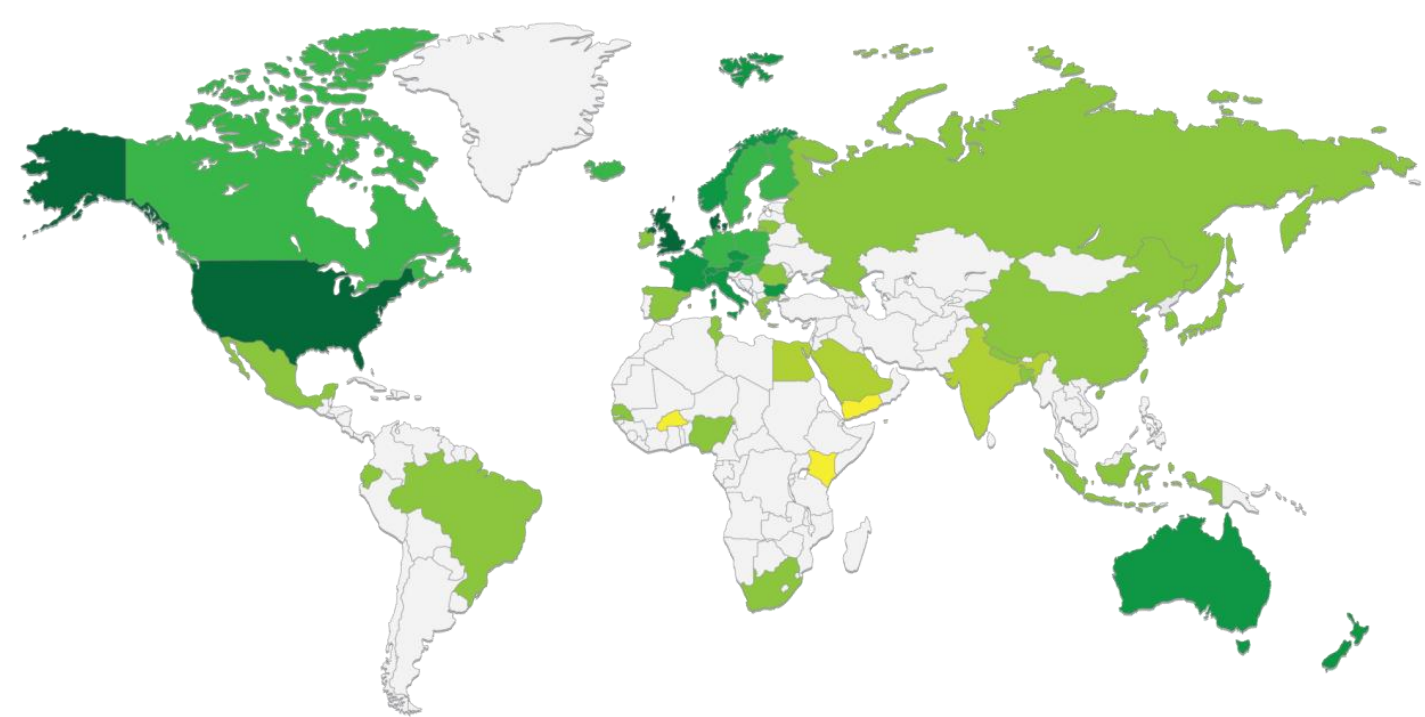

Figure 9: Open data heat map

* Darker shades of green indicate more openness

In scoring terms, the index is depicted thus in Figure 10, is sorted by the country ranking with the first rank claimed by the UK with a score of 940 and closely followed by the USA with a score of 855 . 


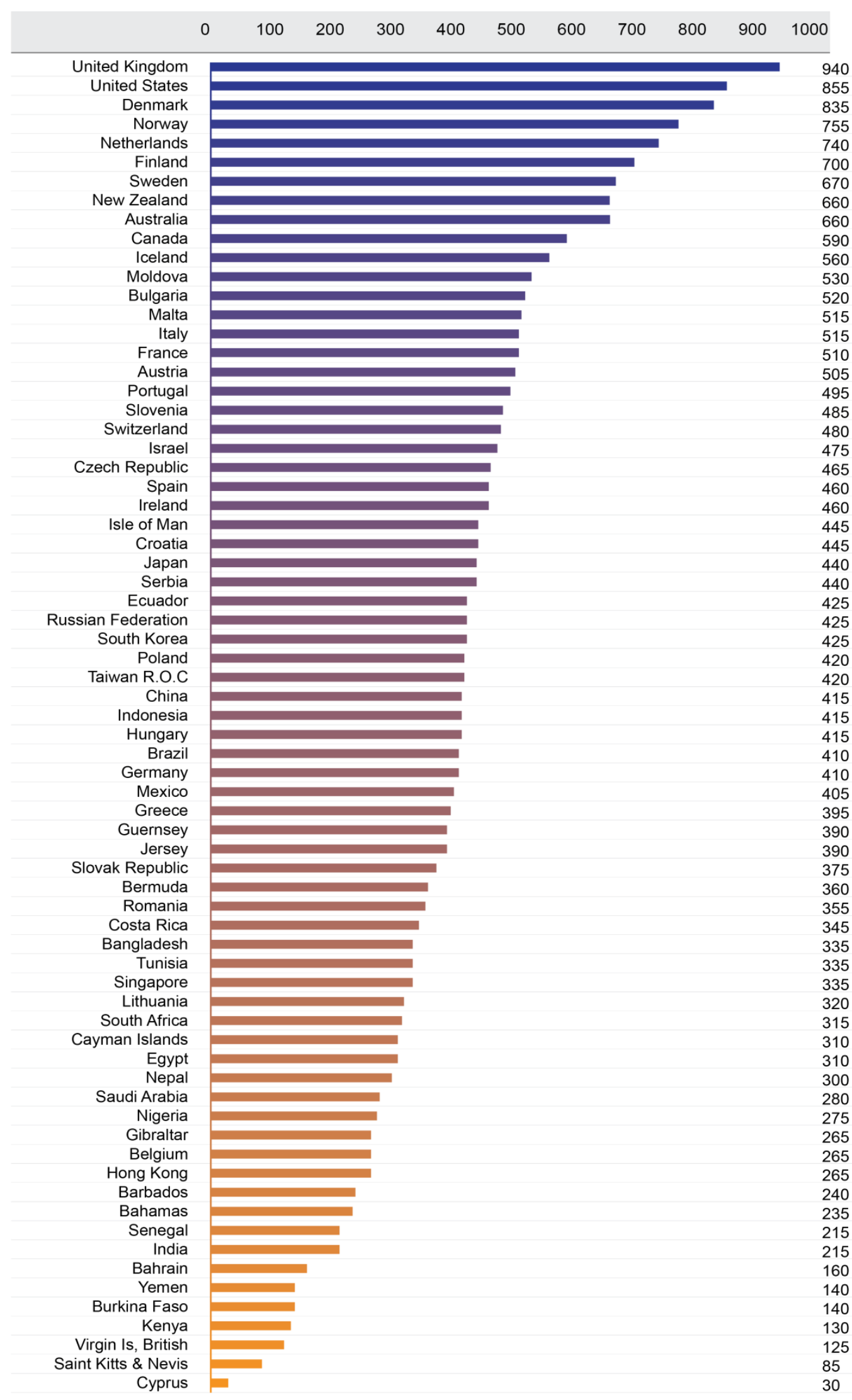

Figure 10: Open Data Country Index Score

Source: Open Knowledge Foundation 


\section{Macrothink}

There are several factors that the Open Knowledge Foundation used in determining the openness index. The scores were constructed by considering data availability in the public domain for ten types of data sets:

1. Transport and timetables for public transport,

2. Government budget,

3. Government spending,

4. Election results,

5. Company register,

6. National map,

7. National statistics,

8. Legislation,

9. Postcodes/ zip codes, and

10. Emissions.

These data sets were scored for nine factors:

1. Existence: does the data exist?

2. Format: is it in digital format?

3. Availability: is it publicly available?

4. Online: is it available online?

5. Cost: is it free of cost?

6. Machine readable: is it in computable format or a human read only (pdf)?

7. Bulk data: is it available in bulk as a consolidated data set?

8. Licensing: is it free of licensing or as per open licensing definition?

9. Currency: is the data current or outdated? 


\section{Ml Macrothink}

A snapshot is depicted in Figure 11 below.

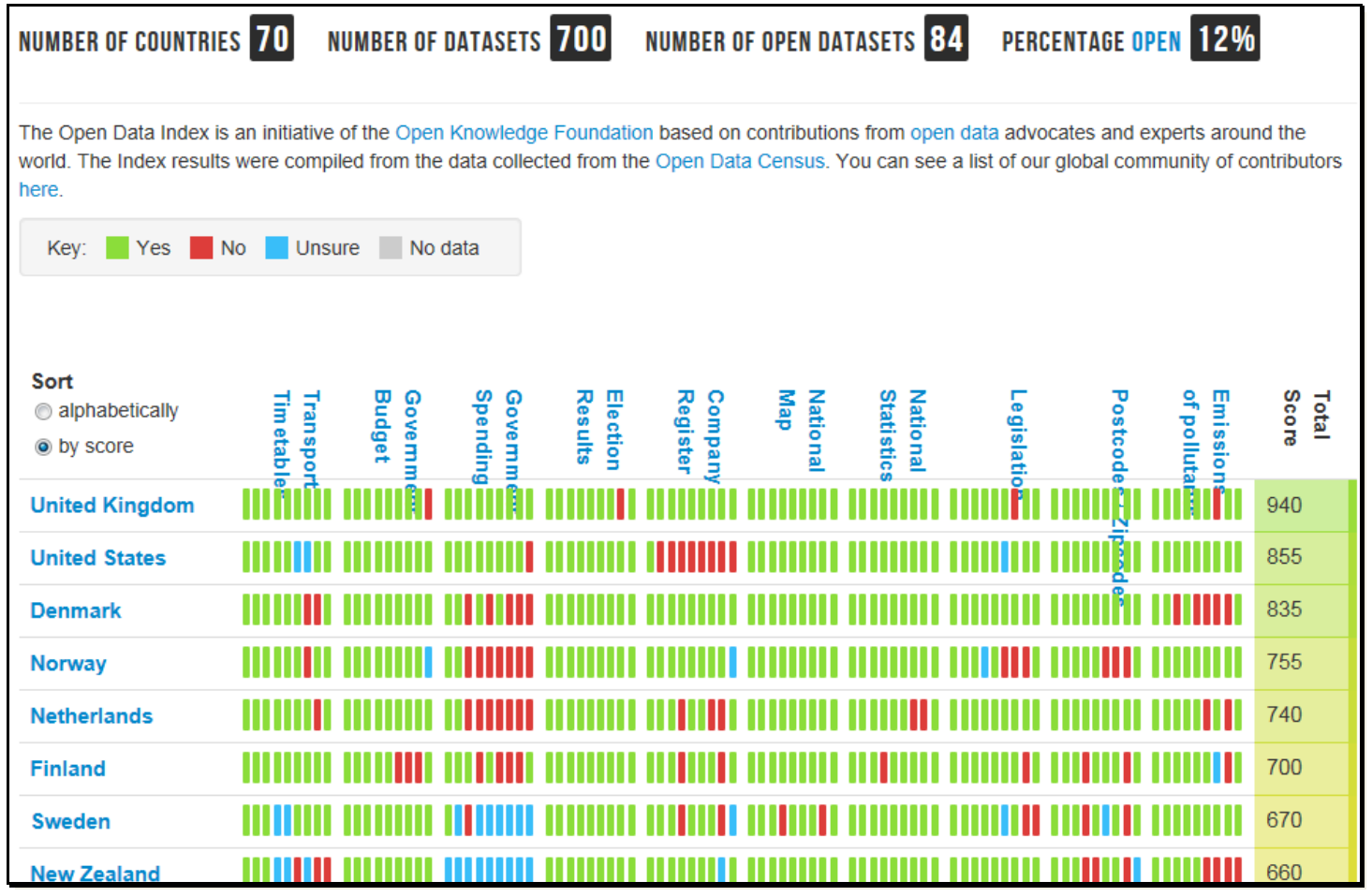

Figure 11: Government Open Data Measurement Index

Source: Open Knowledge Foundation

The United Kingdom ranked 1st based on the criteria explained above with a total of 940 points scored. It scored $100 \%$ in transport, $90 \%$ in government budgets, $100 \%$ in government spending data, $70 \%$ in election results, $100 \%$ in company data, $100 \%$ in national map data, $100 \%$ in national statistics, $90 \%$ in legislation data, $100 \%$ for postal codes and $100 \%$ for emission data.

It is interesting to observe that the top 10 countries as per the open data index are the first world countries and the bottom lot comprises of Barbados, India, Bahrain, Burkina Faso, Yemen, Kenya, Virgin Islands, St Kitts and Cyprus in that order. See also Figure 12 below. 


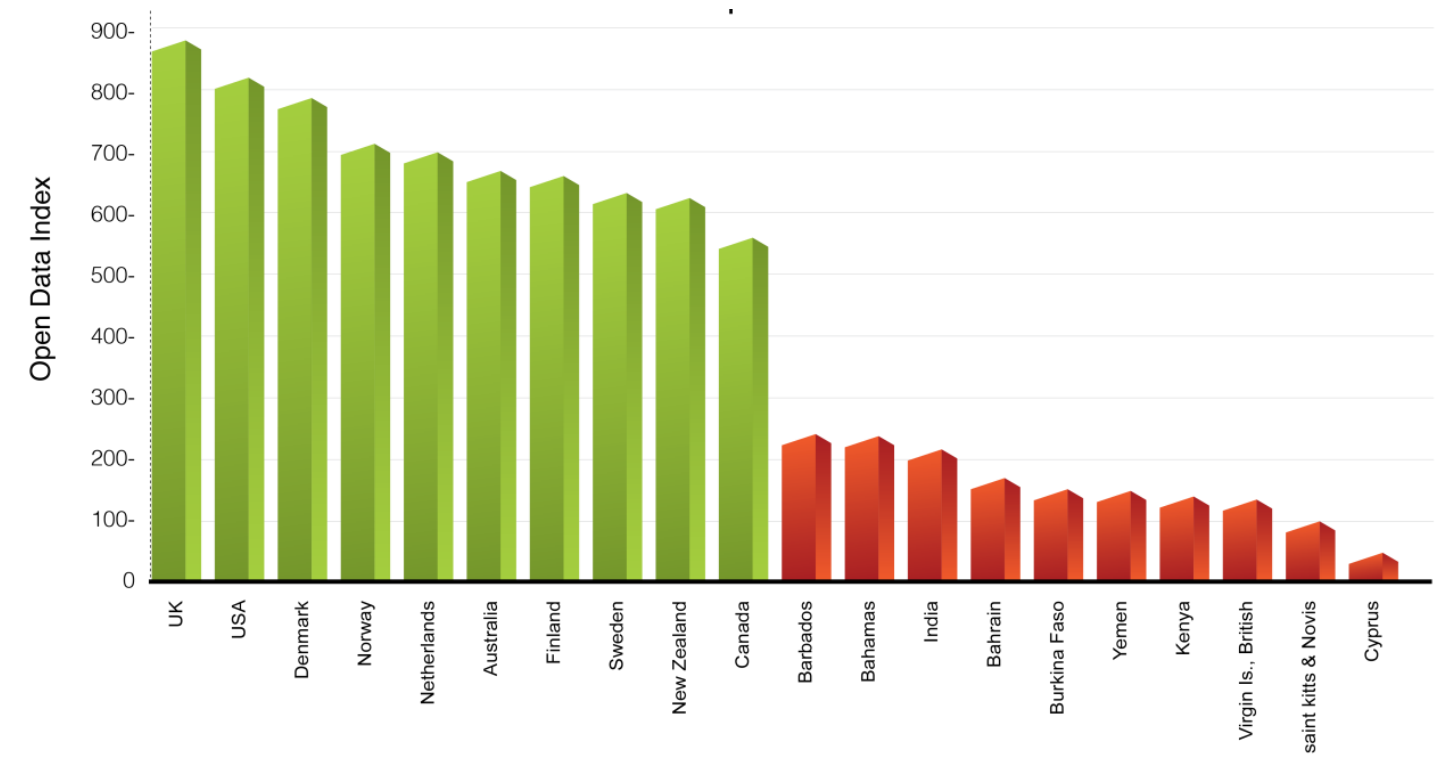

Figure 12: Open Data Index - Top 10 and Bottom 10 countries

Source: Open Knowledge Foundation

What we can understand from the above, is that the more evolved the orientation of citizen participation in governance process, we find such the same governments more evolved in data dissemination in public domains. The keyword is the evolution - the more evolved the government, the more evolved the transparency. Governments showcasing their open data initiatives refer to not only to operational transparency, but they argue that it contributes to building citizens confidence in their governments. As such, there is globally growing interest at all levels of government to increase access to and use of government data in support of good governance (OECD, 2003; OMB, 2009, 2010).

In the next section, we present a case from one of the emerging markets in the Arab world that is setting standards for best practices in governance models; United Arab Emirates (UAE). The case illustrates how the UAE government envisages to use open data to develop decision support models to improve citizens quality of life.

\section{UAE Case: Decision Support Models based on Open Data}

The UAE is considered among the highest investing countries in adopting and implementing progressive ICT in its government and expanding its use to all segments of the economy and society (Bilbao-Osorio et al., 2013). According to the UN eGovernment Survey released in 2012, UAE scored 6th in the eParticipation index against 86th in the 2010 survey (UNDP, 2012). It also scored $11^{\text {th }}$ in the e-participation index assessment conducted by the World Bank in 2013 that measures the scale, quality, relevance, and usefulness of government websites in providing online information and participatory tools and services to their citizens (Bilbao-Osorio et al., 2013). 


\section{Macrothink}

Government design wise, UAE has seven Emirates and each Emirate has its independent e-government authority and thus, they operate on a 7+1 model i.e., a federal government with seven local emirates. See also Figure 13. The open data model for the UAE government thus follows the same model.

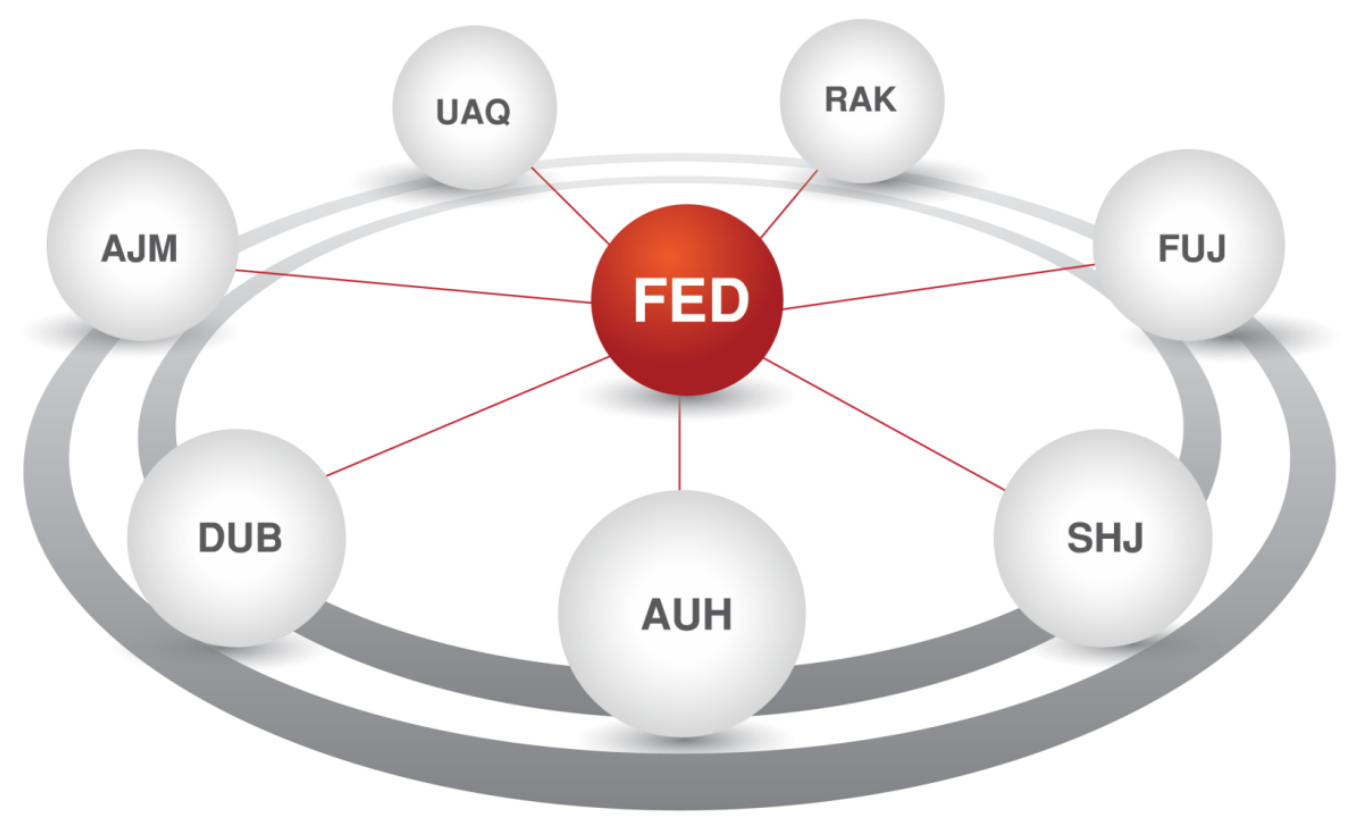

Figure 13: UAE e-Government: 7+1 Model

Each e-government authority aggregates its e-services into an Emirates government portal thus enabling a single window for services on the web. The official open government data site in the UAE, also referred to as 'bayanat', provides consolidated links to open data in UAE. A lot of data is catalogued and indexed as per different subjects (Bayanat, 2014). See also Figure 14. 


\section{$\Lambda$ Macrothink}

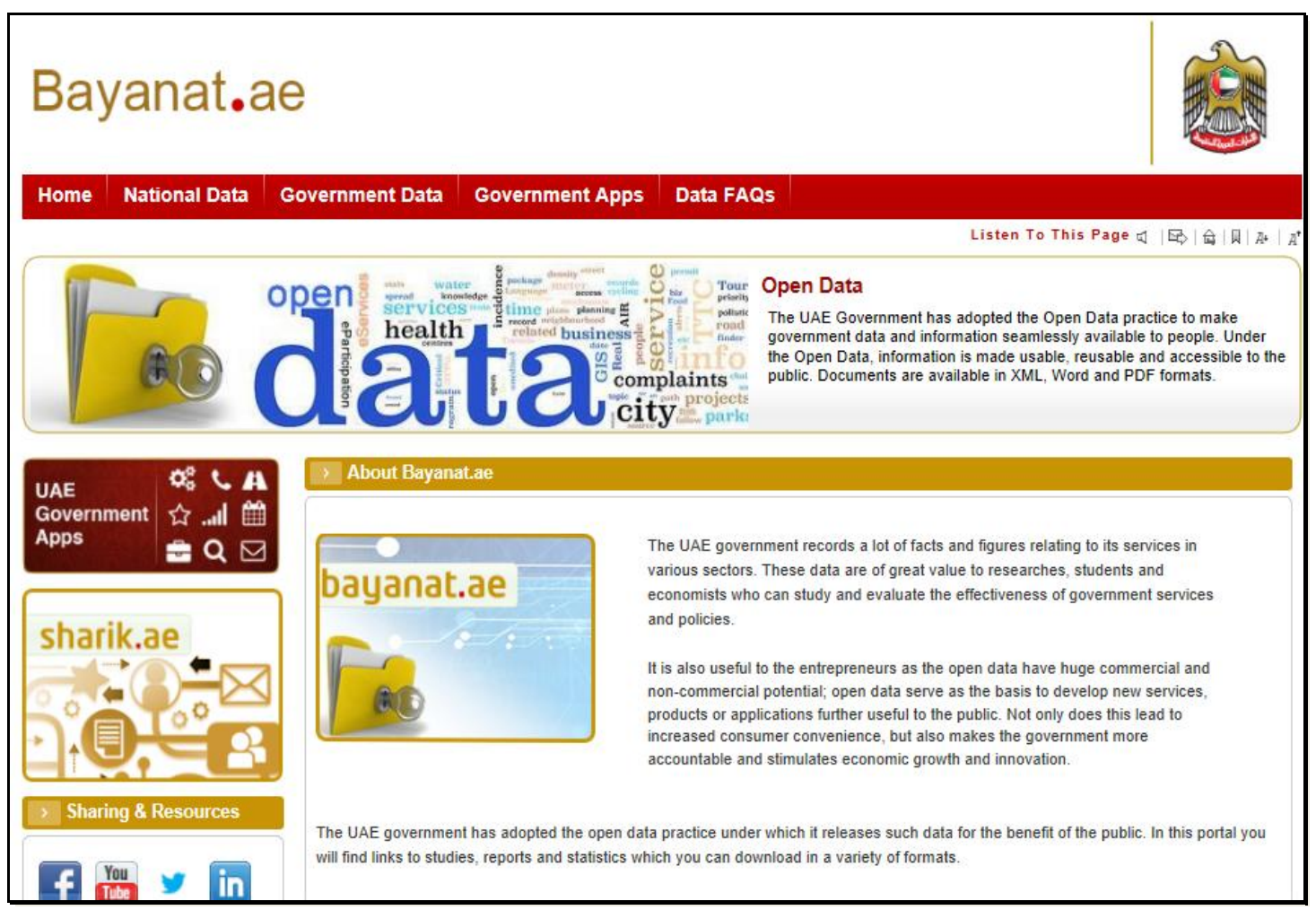

Figure 14: UAE open data portal

Source: www.bayanat.ae

The open data publication of UAE spans various topics spanning economic and demographic data at the national level to aggregated links to many federal ministries. There is a concerted effort now to enable each Emirate to follow suit and start publishing relevant data in the public domain. The government is diligently working towards applying these datasets and is actively promoting private sector entities to develop applications based on these various data sets. Efforts are also on to provide visualization tools for users for them to assess the applicability of data for their needs.

On a global scale, there have been many models put forward that demonstrate a decision-making process which essentially revolve around (1) information, (2) intelligence and (3) choice that lead to a decision. Though every decision making is characterized by these three parameters, at the national level, there are few models that aptly provide a comprehensive framework that is practically implementable.

In UAE, the government is working with a citizen centric model for decision making that embraces the principles of good governance and values that the nation stands for. Bound by national security and economic policies and driven by the national vision, the decision making in the UAE government strives to provide better quality of life for all the citizens and residents in the country. Figure 15 depicts the six layer model of the UAE government decision-making which is based on the country's 2021 vision $^{7}$ (UAE Vision 2021). This

\footnotetext{
${ }^{7}$ UAE Vision 2021 is the highest reference strategy that provides the strategic vision of the country to be one of the best countries in the world. The 2021 vision envisages development of a knowledge-based economy that will be diverse and flexible led by skilled professional Emiratis citizens. The vision contains four important components with detailed objectives
} 


\section{Macrothink}

represents the context in which open data is expected to function and impact the decision making process at the national level.

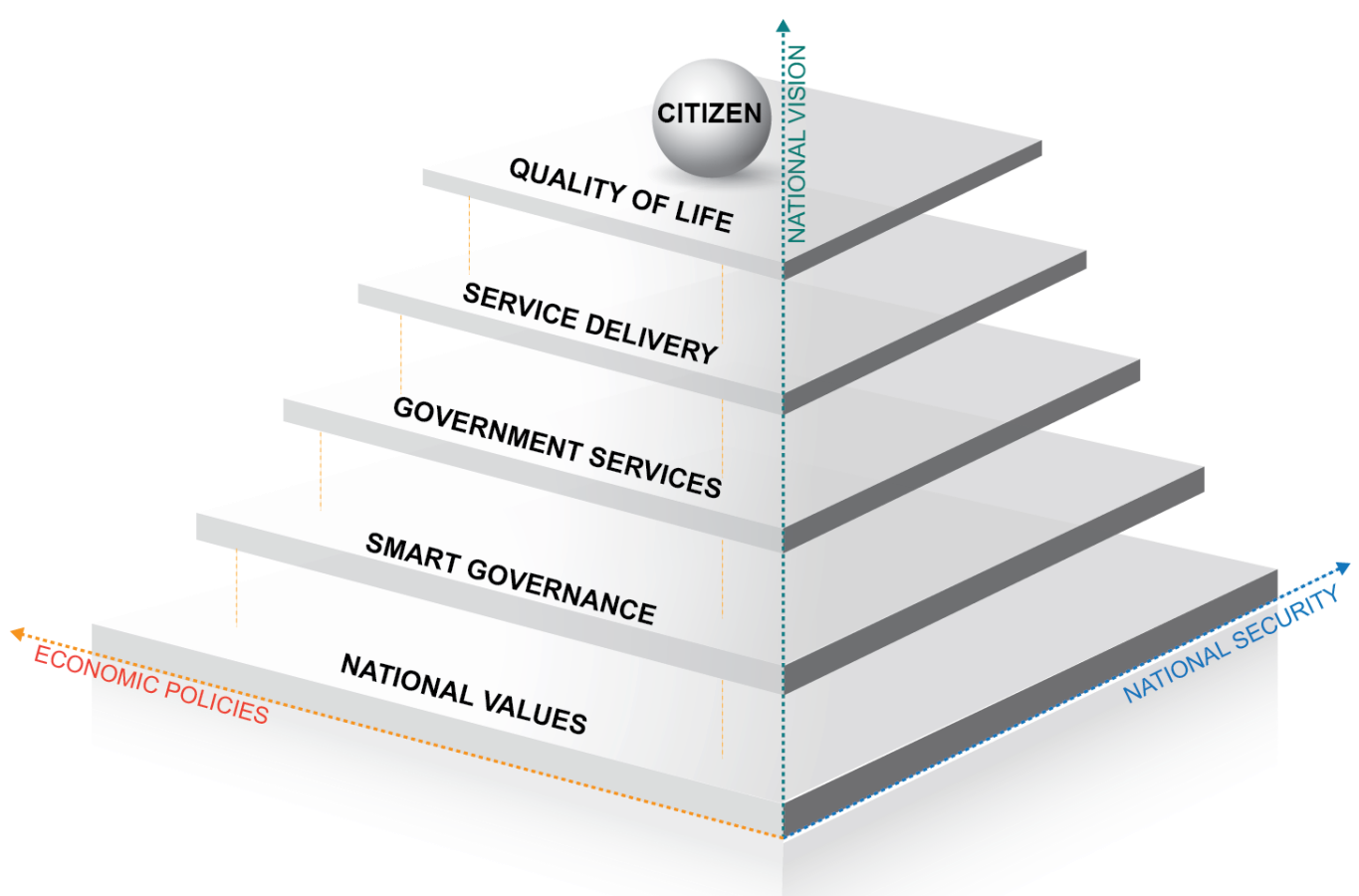

Figure 15: Six Layers of UAE National Decision Support Model

This model is based on the well-known Simon model for decision making which states that any rational decision is a result of a logical process that is based on a choice reached by applying or processing available information using wisdom and intelligence (Simon, 1976). See also Figure 16.

related to national identity, economy, education and health. It seeks to make the UAE a land of ambitious and confident people who hold on to their heritage; a strong federation; a competitive economy led by creative and knowledgeable Emiratis; and finally a high quality of life in a generous and sustainable environment. http://www.vision2021.ae/ 


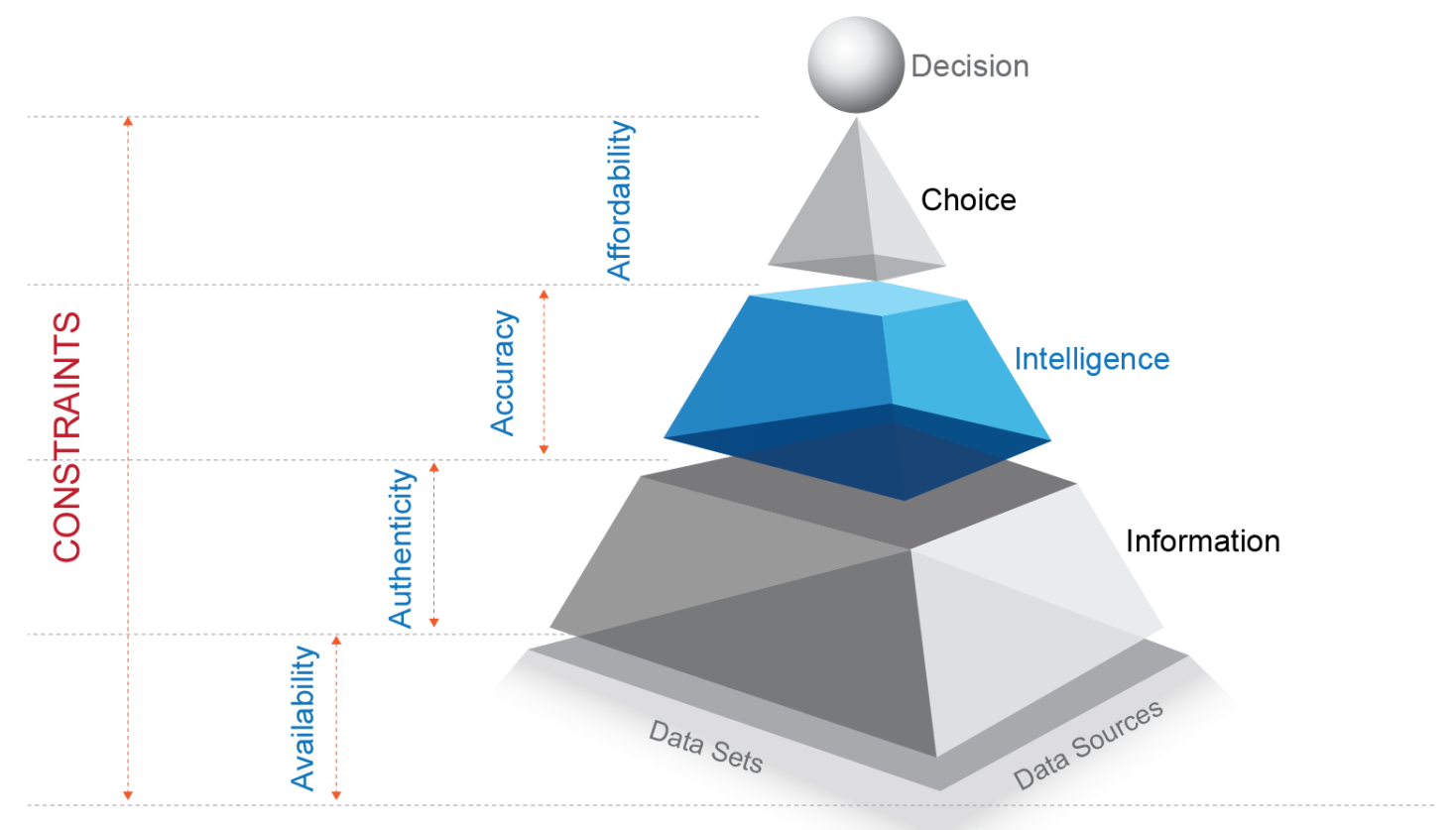

Figure 16: Open Data in National Decision Support Model

There are many constraints though that may characterize decision-making especially in the public administration and national decision making. Availability of raw data and the ability to process it into information is the basic constraint. The authenticity and the accuracy of the processed information depends on the quality of data and the intelligence of the decision making process (and NOT the intelligence of the decision makers). The quality of data in turn depends on the data collection methods. This raises the issue of affordability.

This is precisely the point where government data could make the difference. A government, by default, works for its citizens and thus generates a huge amount of data. This data is then placed in the public domain, authenticated by the respective government departments. E-government portals then aggregate all this data into one single portal for ease of access. A catalogue of data further serves the purpose of meaningful navigation. It is in this context that open data makes a significant impact on the decision making and supports the decisions at the national level.

In general terms, the key drivers for the open data initiative in the UAE government are three fold:

1. improve national decision support system by enabling access to large quality data sets,

2. improve the transparency in government operations to enable higher efficiencies in service delivery, and;

3. improve the communicability of information and enable seamless flow of data. 


\section{Macrothink}

See Figure 17.

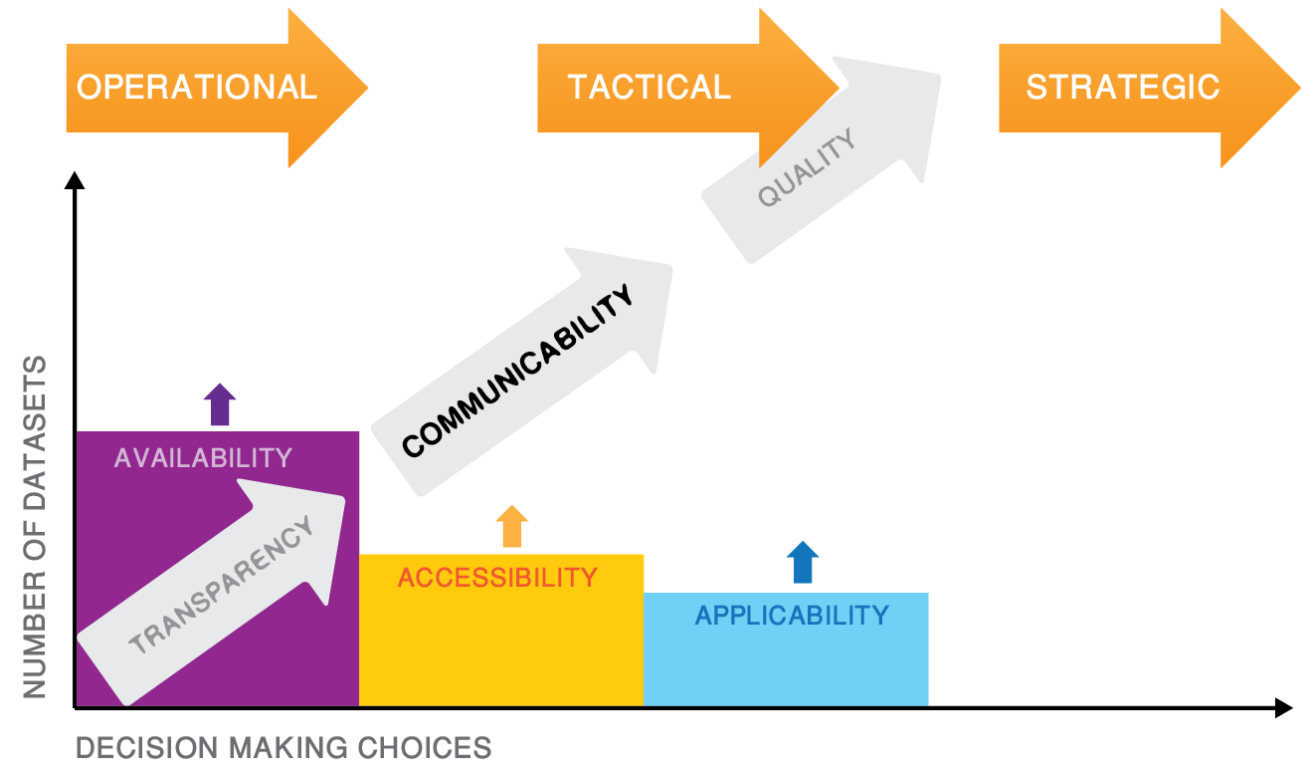

Figure 17: Key Drivers for Open Data in UAE

This is based on the assumption that the larger the number of datasets, the more is the information that can be processed. Placing the data sets openly as aggregated open data on e-government portals ensures accessibility. Good cataloguing and indexing will enable decision makers to use intelligent machine readable systems to qualify this data and assess the applicability for resolving any issue or a problem. This would thus contribute to all the three types of decision making; operational, tactical and strategic decision making needs. See also Figure 18.

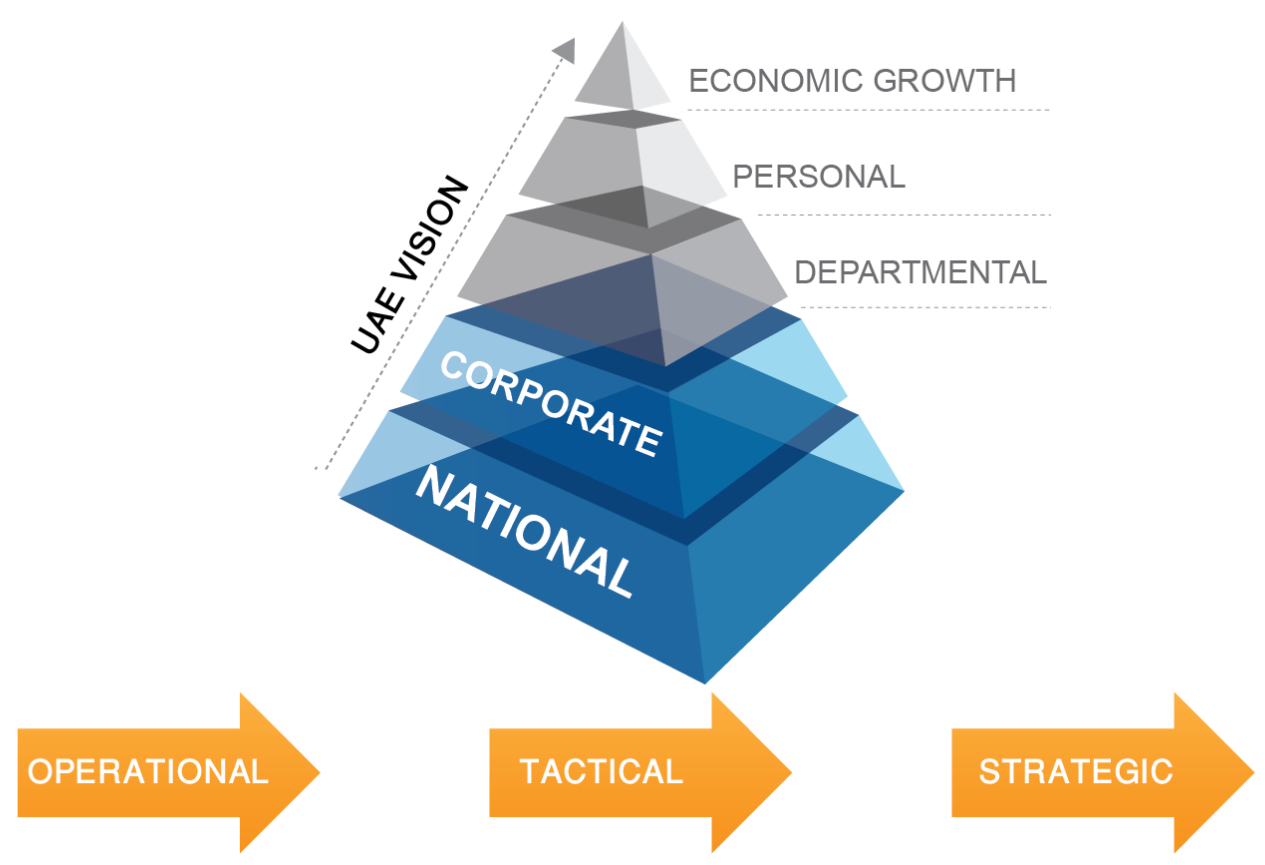


Figure 18: UAE Vision of Decision Making Enablement

UAE government efforts are not just to enable efficient government decision making, but also facilitate informed decision making at the corporate levels. Availability and accessibility of authentic information, especially made available from government sources would help organizations to make crucial decisions. These decisions would contribute to successful corporate strategy fulfillment and thereby economic growth. This represents the vision of the UAE.

\section{Discussion and Conclusion}

"There is no turning back the clock on our interconnected world, but we could jeopardize its benefits if we fail to invest in a trusted data environment". (Richey, 2013)

We can establish from our reading in existing literature and our experience in the government field, that calls for more government data to be in placed in public domain, is largely based on the view that it will lead to higher levels of transparency and accountability in operations. The same views expect that this will positively impact and improve citizen participation and more importantly enable social and economic value realization for both government and citizens alike with the core focus being the citizen happiness and wellbeing. We completely subscribe to such mindsets.

With transparency and citizen participation comes cooperation. The cooperation is not just intra-organization but also inter-organizational. Collaboration and cooperation then becomes a norm than competition.

Open data then presents an opportunity at the national and thereby the regional and international levels of collaboration with problem and solution sharing. This is the answer to the precarious question for government data dissemination in the public domain. It is imperative that for governments to evolve to the next stage of citizen services - citizen happiness - data needs to be shared and shared proactively. See also Figure 19. Arguably, we see this as the easiest path for knowledge assimilation and congregation and the development of what is so called: knowledge economies. 


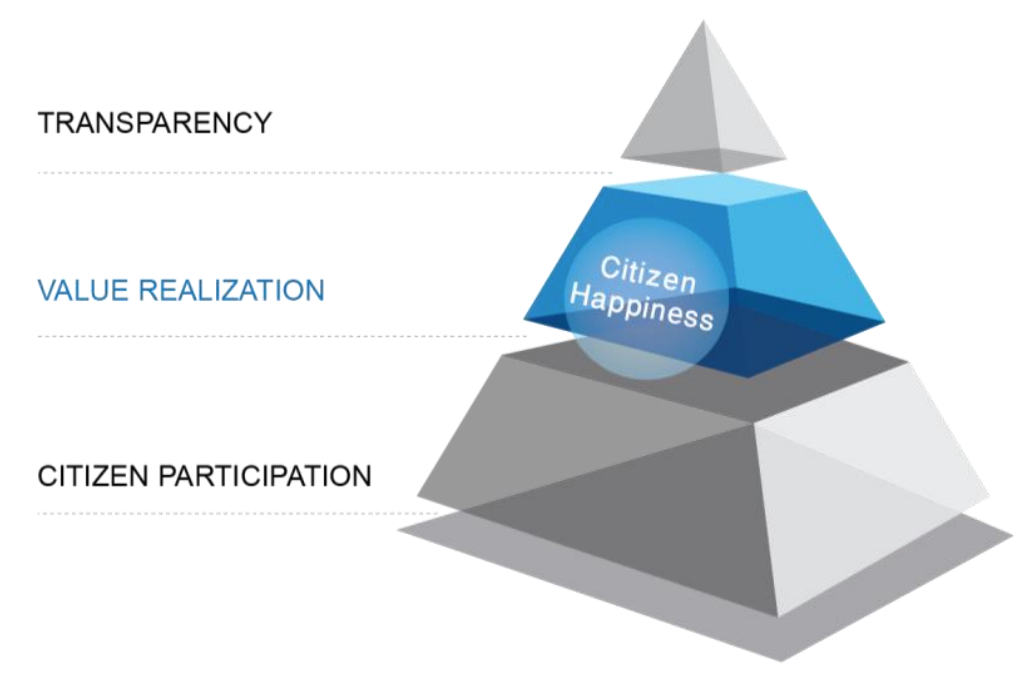

Figure 19: Citizen Centric Government Evolution Pyramid

Yet to remember that placing government data is just one small part of the whole. It is not just any data that is put out in the open. More often than not we find that data that is published thoughtlessly can cause more harm than good. Governments need to ensure that they strategize government data publication and thus the open government strategy needs to be put in place first.

Four of the key drivers of government data strategy are depicted in Figure 20 below. Such strategy should serve to collaborate and enhance value of data with information enrichment, and setup and implement a clear communication strategy with data stakeholders to transform data to valued information.

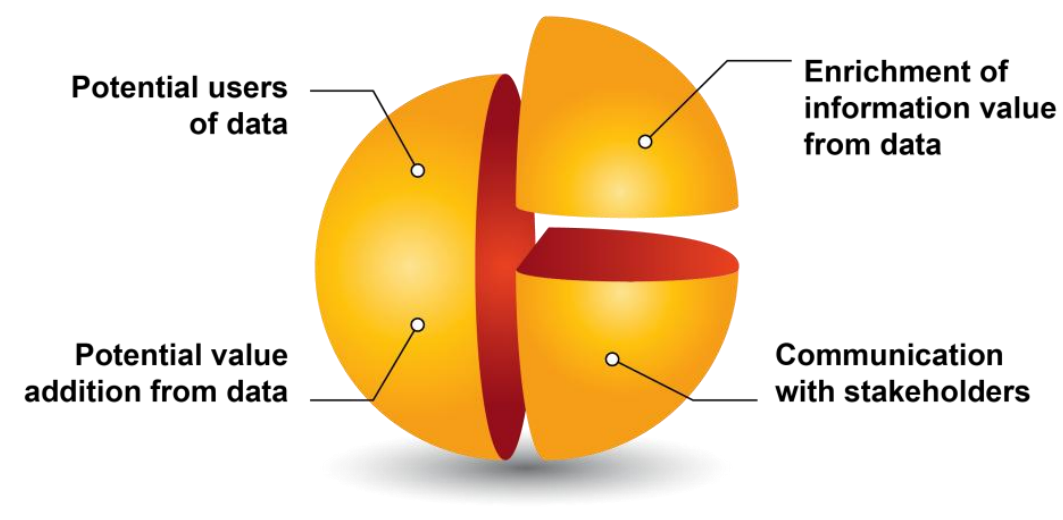

Figure 20: Key Drivers for Government Data Strategy

Here is where public-private partnerships come to the fore yet again that could potentially aid this transformation. See Figure 21. Governments need to encourage private participation in building meaningful information for potential users. While it would be great if government dons the role of the information provider as against the data provider, it would be highly impractical to generate information; simply because there are too many potential stakeholders out there seeking information. 


\section{Macrothink}

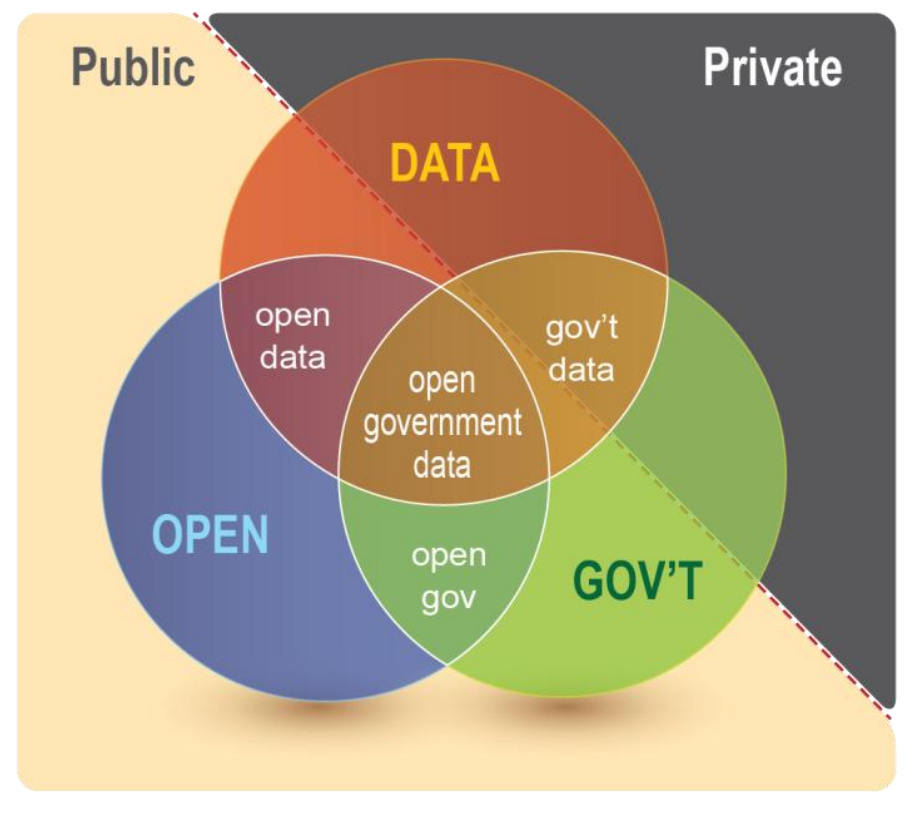

Figure 21: Private Sector and User Involvement

This generates newer opportunities for private entrepreneurs to provide information services using various data sets. Governments need to encourage and work closely with such service providers to setup infrastructure and tools for data visualization and provide information services. This could lead to development and further publication of research to resolve national issues. The information can contribute to the decision support systems or even better be the decision support system for the betterment of the citizens in the country.

In conclusion, while there already are available numerous data sets in the public domain and more are set to be published, it is imperative that this data be wisely used. The goals of the data dissemination should be for transforming the quality of life of normal citizens. This needs to be driven by a sound strategy with a clear vision- the vision of bettering citizens' quality life.

\section{References}

Bayanat (2014). Open Data Portal, UAE Government. [Online] Available: http://www.government.ae/en/web/guest/uae-data

Berners-Lee, T. (2006). Linked Data. The World Wide Web Consortium (W3C). [Online] Available: http://www.w3.org/DesignIssues/LinkedData

Bertot, J.C., Jaeger, P.T., Munson, S. and Glaisyer, T. (2010). Engaging the Public in Open Government: Social Media Technology and Policy for Government Transparency. [Online] Available:

http://tmsp.umd.edu/TMSPreports_files/6.IEEE-Computer-TMSP-Government-Bertot-10081 7pdf.pdf 


\section{$\triangle$ Macrothink}

Journal of Public Administration and Governance ISSN 2161-7104 2014, Vol. 4, No. 3

Bilbao-Osorio, B., Dutta, S. and Lanvin, B. (Eds.) (2013). The Global Information Technology Report 2013: Growth and Jobs in a Hyperconnected World. World Economic Forum. [Online] Available: http://www.kig.gv.at/Portal.Node/kig/public/Content/files/aktuelles/NRI_2013.pdf

Chambers, L., Evans, L., Hyde, A., Lee, K., Lindenberg, F., Mehmedbasic, D., Mitra, S., Ramirez, F., Smith, S. (2012). Spending Data Handbook, OpenSpending. [Online] Available: http://content.openspending.org/resources/handbook/spending-data-handbook.pdf

Deloitte (2013). Market Assessment of Public Sector Information, A report for the Department for Business, Innovation and Skills, UK Government. [Online] Available: https://www.gov.uk/government/uploads/system/uploads/attachment_data/file/198905/bis-13743-market-assessment-of-public-sector-information.pdf

ePSIPlatform (2014). The European Public Sector Information Platform. [Online] Available: http://epsiplatform.eu/

European Commission (2011). Open data: An engine for innovation, growth and transparent governance, Communication form the Commission to the European Parliament, the Council, The European Economic and Social Committee and the Committee of the Regions, Brussels. [Online] Available: http://eur-lex.europa.eu/legal-content/EN/TXT/PDF/?uri=CELEX:52011DC0882\&from=EN

European Commission (2014). Open Data, Digital Agenda for Europe, a Europe 2020 Initiative. [Online]

Available: http://ec.europa.eu/digital-agenda/en/public-sector-information-raw-data-new-services-and-pr oducts

Gartner (2013). Worldwide Government IT Spending Flat in 2013. [Online] Available: http://www.gartner.com/newsroom/id/2518815

Gartner (2014). Government IT Spending in Middle East \& Africa to Reach US \$11.9 Billion in 2014. [Online] Available: http://www.gartner.com/newsroom/id/2698117

Gerber, A, Molefo O, Van der Merwe, A. (2010). Documenting Open-Source Migration Processes for Re-Use. Proceedings of the SAICSIT 2010 Conference - Fountains of Computing Research, Kotze, P., Gerber, A., van der Merwe, A., and Bidwell, N. (ed.). ACM Press, p. 75 - 85,978-1-60558-950-3.

Gray, J. (2011). European Commission launches Open Data Strategy for Europe. Open Knowledge Foundation Blog. [Online] Available: http://blog.okfn.org/2011/12/12/european-commission-launches-open-data-strategy-for-europ e/

Grossman, L. (1998). New Free License to Cover Content Online, Netly News, July 18. [Online] Available: http://web.archive.org/web/20000619122406/http://www.time.com/time/digital/daily/0,2822, 621,00.html 


\section{$\triangle$ Macrothink}

Journal of Public Administration and Governance ISSN 2161-7104

Helbig, N., Cresswell, A.M., Burke, G.B. and Luna-Reyes, L. (2012). The Dynamics of Opening Government Data. Center for Technology in Government, The Research Foundation of State University of New York, New York, USA. [Online] Available: http://www.ctg.albany.edu/publications/reports/opendata/opendata.pdf

HM Government (UK) (2012). Open Data White Paper: Unleashing the Potential. [Online] Available: http://data.gov.uk/sites/default/files/Open_data_White_Paper.pdf.

Hogge, B. (2010). Open Data Study: New Technologies. [Online] Available: http://www.transparency-initiative.org/wp-content/uploads/2011/05/open_data_study_final1. pdf

Lakhani, K. R., \& von Hippel, E. (2003). How Open Source Software Works: Free User to User Assistance. Research Policy, 32, 923-943.

Lee, G. and Kwak, Y.H. (2012). An Open Government Maturity Model for social media-based public engagement. Government Information Quarterly, Vol. 29, No. 4, pp. 492-503.

Levine, S.S., and Prietula, M.J. (2013). Open Collaboration for Innovation: Principles and Performance. Organization Science. doi: 10.1287/orsc.2013.0872 [Online] Available: http://doi.org/rfb

Manyika, J., Chui, M., Groves, P., Farrell, D., Van Kuiken, S. Doshi, E.A. (2013). Open data: Unlocking innovation and performance with liquid information. McKinsey Global Institute.

McKinsey (2013). Open Data: Unlocking Innovation and Performance with Liquid Information. [Online] Available: http://newamerica.net/sites/newamerica.net/files/events/MGI_Open_data_Full_report_Oct_2 013.pdf

ODI (2014). The Open Data Institute, London, UK. [Online] Available: http://www.theodi.org/

OECD. (2003). Public Sector Modernisation: Open Government, Policy Brief. pp. 1-8. [Online] Available: http://www.oecd.org/dataoecd/1/35/34455306.pdf.

OKFN (2014) The Open Knowledge Foundation. [Online] Available: http://okfn.org/

OMB (US Office of Management and Budget). (2009). Open Government Directive. [Online] Available: http://www.whitehouse.

gov/sites/default/fi les/omb/assets/memoranda_2010/m10-06.pdf

OMB (US Office of Management and Budget). (2010). Digital Government: Building a 21st Century Platform to Better Serve the American People. [Online] Available: http://www.whitehouse.gov/sites/default/fi les/omb/egov/digital-government/digitalgovernment-strategy.pdf.

Open Data Index (2014). Open Knowledge Foundation. [Online] Available: https://index.okfn.org/ 
Open Knowledge Foundation (2012). What is Open Data? Open Data Handbook. [Online] Available: http://opendatahandbook.org/en/what-is-open-data/

Richey, E. (2013). Will the promise of 'Big Data' be realised?, World Economic Forum Blog on Big Data. [Online] Available: http://forumblog.org/2013/01/will-the-promise-of-big-data-be-realised/

Rohlin, R. (2014). Open Data, Knowledge Innovation and Capacity. [Online] Available: www.worldwewant2015.org/file/428974/download/466827

Schöpfel, Joachim; Prost, Hélène (2013). 'Degrees of secrecy in an open environment. The case of electronic theses and dissertations'. ESSACHESS - Journal for Communication Studies 6 (2). ISSN 1775-352X.

Schwalje, W. and Aradi, W. (2013). An Arab Open Government Maturity Model for Social Media Engagement. Tahseen Consulting. [Online] Available: http://bit.ly/1grDAxk

Schwartz, M. (2012). Directory of Open Access Books Goes Live, Library Journal, April 13. [Online] Available: http://lj.libraryjournal.com/2012/04/academic-libraries/directory-of-open-access-books-goes-1 ive/

Simon, H. (1976). Administrative Behavior (3rd ed.), New York: The Free Press.

Suber, P. (2011). "Open Access Overview". Earlham.edu. Retrieved on 2011-12-03.

The Open Data Handbook (2012). Open Knowledge Foundation. [Online] Available: http://opendatahandbook.org/en/

Ubaldi, B. (2013). Open Government Data: Towards Empirical Analysis of Open Government Data Initiatives, OECD Working Papers on Public Governance, No. 22, OECD Publishing. [Online] Available: http://dx.doi.org/10.1787/5k46bj4f03s7-en

UNDP (2012). United Nations EGovernment Survey 2012: eGovernment for the People. retrieved April 11, 2012. [Online] Available: http://www2.unpan.org/egovkb/global_reports/12report.htm.

UNDP (2013). ICTs and e-governance in UNDP: 2013 status report. https://www.undpegov.org/mapping/2013

US White House (2013). Executive Order -- Making Open and Machine Readable the New Default for Government Information. [Online] Available: http://www.whitehouse.gov/the-press-office/2013/05/09/executive-order-making-open-and-m achine-readable-new-default-government-

Wiley, D. (1998). Open Content, OpenContent.org. [Online] Available: http://web.archive.org/web/19990128224600/http://www.opencontent.org/home.shtml

World Bank (2014) The World Bank Open Data. [Online] Available: http://data.worldbank.org/ 


\section{Macrothink}

WWWF (2014). World Wide Web Foundation. [Online] Available:

http://www.webfoundation.org/

\section{Copyright Disclaimer}

Copyright reserved by the author(s).

This article is an open-access article distributed under the terms and conditions of the Creative Commons Attribution license (http://creativecommons.org/licenses/by/3.0/). 